\title{
Antiangiogenic Herbal Composition Ob-X Reduces Abdominal Visceral Fat in Humans: A Randomized, Double-Blind, Placebo-Controlled Study
}

\author{
Jae-Heon Kang, ${ }^{1}$ In Sun Jeong, ${ }^{1}$ and Min-Young Kim $\mathbb{D}^{2}$ \\ ${ }^{1}$ Inje University Seoul Paik hospital, Seoul 04551, Republic of Korea \\ ${ }^{2}$ AngioLab, Inc., Daejeon 34016, Republic of Korea \\ Correspondence should be addressed to Min-Young Kim; mykim@angiolab.co.kr
}

Received 28 September 2017; Revised 2 April 2018; Accepted 8 April 2018; Published 28 May 2018

Academic Editor: Filippo Fratini

Copyright (c) 2018 Jae-Heon Kang et al. This is an open access article distributed under the Creative Commons Attribution License, which permits unrestricted use, distribution, and reproduction in any medium, provided the original work is properly cited.

\begin{abstract}
Adipose tissue growth is angiogenesis-dependent, and angiogenesis inhibitors can regulate adipose tissue mass by cutting off the blood supply. We examined whether antiangiogenic herbal composition Ob-X can reduce fast-growing abdominal fat, especially visceral fat in humans by inhibiting angiogenesis. Eighty abdominally obese subjects (body mass index: $25-29.9 \mathrm{~kg} / \mathrm{m}^{2}$, waist circumference: exceeding $90 \mathrm{~cm}$ for males and $85 \mathrm{~cm}$ for females) participated in a 12-week randomized, double-blind, placebocontrolled human study to evaluate the efficacy and safety of Ob-X. $690 \mathrm{mg}$ of Ob-X was administered orally twice a day. The Ob-X group showed a noticeable reduction in visceral fat of $20.5 \%$ after the 12 -week treatment as compared to baseline measured by computed tomography. The change in visceral fat in the $\mathrm{Ob}-\mathrm{X}$ group was statistically significant as compared to the placebo group $(\mathrm{p}=0.0495)$ and 1.9 times higher than in the placebo group. Therefore, angiogenesis inhibitor Ob-X has the potential to improve obesity-related metabolic syndrome by reducing dangerous visceral fat.
\end{abstract}

\section{Introduction}

Obesity, particularly abdominal obesity, plays an important role in the pathogenesis of metabolic disorders and cardiovascular diseases, including type 2 diabetes $[1,2]$, hypertension $[3,4]$, dyslipidemia [5], and coronary artery disease [6]. Accumulated fat in the intra-abdominal or visceral depots is closely associated with all obesity-related complications, and it has become quite clear that visceral adiposity is more closely associated with obesity-related complications than total adiposity [7-10]. Therefore, decreasing visceral fat is important in preventing or improving obesity-related metabolic diseases.

Angiogenesis is the process of new blood vessel formation from preexisting vasculature. Similar to tumor tissue, adipose tissue growth is angiogenesis-dependent, and adipose tissue mass can be regulated by its vasculature [11-13]. It has been shown that angiogenesis modulates adipogenesis and obesity [14]. Thus, adipose tissue angiogenesis may be a therapeutic target for obesity and metabolic disease [15].
We screened antiangiogenic and MMP-inhibitory activities from herbal extract libraries and found that three herbal extracts of Morus alba L. (Moraceae; white mulberry), Melissa officinalis L. (Lamiaceae; lemon balm), and Artemisia capillaris Thunb. (Compositae; Injin or Yin Chen Hao) showed antiangiogenic and MMP-inhibitory activities [16]. Moreover, the combination of three herbal extracts showed synergistic effect in inhibiting angiogenesis, compared with each extract alone.

Melissa has been used as a medicinal plant to treat nervousness, insomnia, gastrointestinal disorders, herpes virus infection, and Alzheimer's disease [17, 18]. It is well known that aqueous or aqueous ethanolic extract of Melissa contains phenolic compounds. The prominent phenolic compound in Melissa extract is rosmarinic acid, which has a number of interesting biological activities, such as antiviral, antibacterial, antiinflammatory, antioxidant [19], and antiangiogenic [20]. Aqueous white mulberry extract contains 1-deoxynojirimycin, which is known to be one of the most potent $\alpha$-glycosidase inhibitors [21]. A water extract 
of Artemisia capillaris had protective effects against oxidative stress induced liver damage in rats [22]. Each herbal extract was standardized with a reference compound to maintain the quality.

In animal studies, a mixture of three herbal extracts, called $\mathrm{Ob}-\mathrm{X}$, reduced adipose tissue mass in high fat dietinduced obese mice, providing evidence that adipose tissue growth can be inhibited by angiogenesis inhibitor [23]. In addition, the regulation of adipose tissue growth by $\mathrm{Ob}-\mathrm{X}$ altered the expression of genes involved in angiogenesis and the MMP system [23].

$\mathrm{Ob}-\mathrm{X}$ supplementation in high-fat diet-induced obese mice increased the hepatic mRNA levels of the PPAR $\alpha$ target enzymes responsible for fatty acid $\beta$-oxidation [24]. The study demonstrated that $\mathrm{Ob}-\mathrm{X}$ regulates body weight gain, adipose tissue mass, and lipid metabolism, partly through changes in the expression of hepatic PPAR $\alpha$ target genes [24].

In genetically obese $o b / o b$ mice, $\mathrm{Ob}-\mathrm{X}$ also reduced body weight gain and visceral fat mass, without changes in weights of any other organs, demonstrating that $\mathrm{Ob}-\mathrm{X}$ specifically targets adipose tissue [25]. Ob-X suppresses adipogenesis in 3T3-L1 adipocytes by inhibiting differentiation of preadipocytes into adipocytes [26]. These events may be mediated by changes in the expression of genes involved in lipogenesis, angiogenesis, and the MMP system [26]. Thus, antiangiogenic $\mathrm{Ob}-\mathrm{X}$ may provide a possible therapeutic approach to the prevention and treatment of human obesity and related disorders, by reducing adipose tissue.

In the present study, $\mathrm{Ob}-\mathrm{X}$ was evaluated in humans to determine whether it reduces fast-growing abdominal fat, especially visceral fat, by inhibiting angiogenesis.

\section{Materials and Methods}

2.1. Subjects. Healthy volunteers, 19-50 years of age, were recruited. Informed consent was obtained from all the subjects prior to enrolling in the study. A total of 80 volunteers, with a BMI of $25-29.9 \mathrm{~kg} / \mathrm{m}^{2}$ and waist circumference exceeding $90 \mathrm{~cm}$ for males and $85 \mathrm{~cm}$ for females, met the inclusion criteria and enrolled. Exclusion criteria for the study included those on drug therapy, those on a special diet, those taking dietary substitutes for weight loss, and those involved in a diet program within 3 months prior to the start of the study. Hypertensive individuals whose SBP was higher than $160 \mathrm{mmHg}$ or DBP higher than $100 \mathrm{mmHg}$, those taking diuretics, diabetics taking oral hypoglycemic agents or insulin, those with active thyroid disease or hyperlipidemia, those with a history of renal, liver, pancreatic, or chronic inflammatory/infectious diseases, allergic diseases, asthma, heart failure, or malignant tumors, pregnant or lactating women, and volunteers with suspected drug or alcohol abuse or with any clinical condition rendering them unfit to participate were also excluded from the study.

2.2. Preparation of $\mathrm{Ob}-\mathrm{X}$. Ob-X was prepared using food grade aqueous extracts of Morus alba L. (white mulberry), Melissa officinalis L. (lemon balm), and Artemisia capillaris Thunb. (Injin or Yin Chen Hao). The quality of each herbal extract contained in the $\mathrm{Ob}-\mathrm{X}$ was controlled by standardization with reference compounds using highpressure liquid chromatography (HPLC). The corresponding reference compounds are 1-deoxynojirimycin (Morus alba L.), rosmarinic acid (Melissa officinalis L.), and 6,7dimethylesculetin (Artemisia capillaris Thunb.). For the human study, $230 \mathrm{mg}$ of $\mathrm{Ob}-\mathrm{X}$ was filled in one capsule, and $230 \mathrm{mg}$ of dextrin was filled in a capsule, used as placebo, at the GMP facility. The composition of Ob-X in $230 \mathrm{mg}$ is $102.1 \mathrm{mg}$ of white mulberry leaf extract, $102.4 \mathrm{mg}$ of lemon balm leaf extract, and $25.5 \mathrm{mg}$ of Injin extract in powdered form.

2.3. Study Design. Ethical approval for this human study was obtained from the Institutional Review Board at the Inje University Seoul Paik hospital (SIT 240) in 2008 as being in compliance with the Helsinki II Declaration. It was a randomized, placebo-controlled, double-blind, 12-week study. Eighty subjects were enrolled in the study and randomized to receive placebo (1.38 $\mathrm{g}$ of dextrin) or $1.38 \mathrm{~g}$ of $\mathrm{Ob}-\mathrm{X}$ per day for 12 weeks. The daily dose of $\mathrm{Ob}-\mathrm{X}$ was determined by the preliminary human study (data not published). $1.38 \mathrm{~g}$ of $\mathrm{Ob}$ $\mathrm{X}$ contains $0.9 \mathrm{~g}$ of active extracts and $0.48 \mathrm{~g}$ of dextrin as excipient. Subjects were instructed to take 3 capsules (230 $\mathrm{mg} /$ capsule) twice a day in the morning and afternoon, a total of 6 capsules per day (1.38 g). The placebo capsules and $\mathrm{Ob}-\mathrm{X}$ capsules were identical in appearance.

All subjects were scheduled to visit the hospital every 4 weeks from the start of the study. During the study, all subjects were counseled on diet and exercise compliance at every visit from the nutritionist. All subjects were instructed to restrict their total energy intake to 500-kcal deficit of the recommended daily calorie intake and were advised to exercise corresponding to an energy expenditure of $250 \mathrm{kcal}$ per day, three times a week. All subjects were educated to fill out a food diary, and the nutritionist analyzed the food intake of three major nutrients in terms of calorie content, using the nutrition analysis program (CAN pro) at baseline and at 12 weeks.

2.4. Anthropometric Measurement. Baseline characteristics and demographic data were recorded by the medical staff as the subjects entered the study, to evaluate their eligibility. Body weight, height, waist and hip circumferences, BMI, and vital signs, such as systolic and diastolic blood pressure and heart rate measurements, were recorded.

2.5. Laboratory Measurement. White blood cell (WBC), red blood cell (RBC), hematocrit, hemoglobin, and platelet were determined as hematological studies. Creatinine, blood urea nitrogen $(\mathrm{BUN})$, uric acid, calcium $(\mathrm{Ca})$, potassium $(\mathrm{P})$, sodium $(\mathrm{Na})$, potassium $(\mathrm{K})$, chloride $(\mathrm{Cl})$, insulin, aspartate aminotransferase (AST), alanine aminotransferase (ALT), albumin, protein, alkaline phosphatase(ALP), total cholesterol, LDL-cholesterol, HDL-cholesterol, triglyceride, glucose, and C-reactive protein (CRP) were determined as laboratory test items for safety analysis.

2.6. Clinical Assessment. The primary outcome measure of this study was the reduction of abdominal fat at week 12 as 


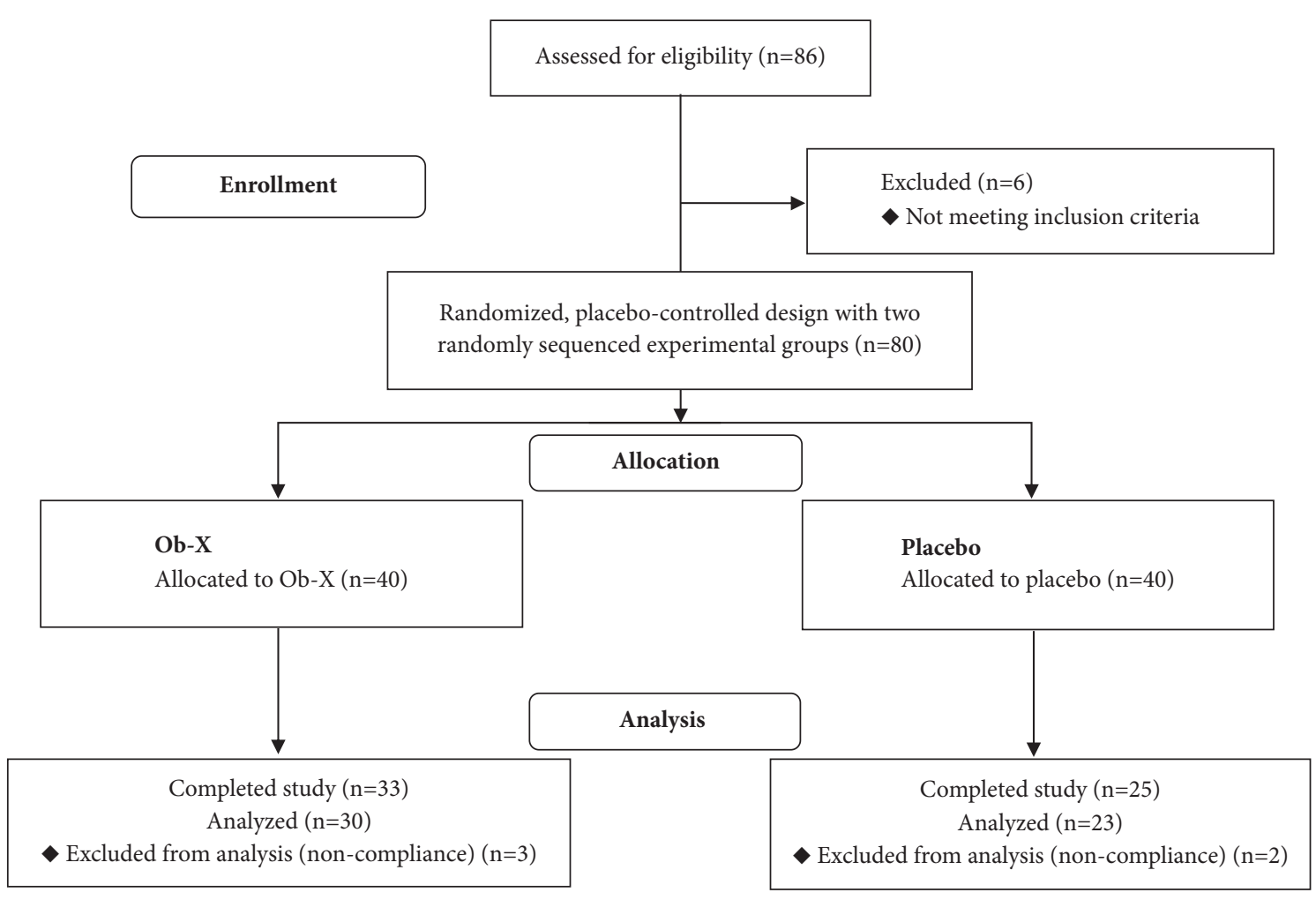

FIgURE 1: CONSORT (Consolidated Standards of Reporting Trials) flow diagram of the recruitment, enrollment, and randomization process.

compared to baseline. Computed tomography was used, on a Siemens CT scanner (Erlangen, Germany), to determine total abdominal fat, visceral fat, and subcutaneous fat areas at baseline and at week 12. An image of the cross section at the L4/L5 intervertebral disc level was obtained and was analyzed using Siemens' software.

Body composition was measured by bioelectric impedance analysis (BIA, BC-418, Tanita, Japan) at baseline and at week 12 .

2.7. Compliance Assessment. Subjects were asked to return all unused capsules in the original bottles every 4 weeks. The returned capsules were counted and the compliance was calculated as the number of capsules actually consumed divided by the number of capsules that should have been used by the end of 12 weeks of treatment. Each subject was considered compliant when taking at least $70 \%$ of $\mathrm{Ob}-\mathrm{X}$ or placebo given.

2.8. Statistical Analysis. The effect of $\mathrm{Ob}-\mathrm{X}$ was assessed by analyzing the $\mathrm{Ob}-\mathrm{X}$ treated group compared with the placebo group. The results are given as mean and standard deviation. The data were processed using the SPSS statistical program, and the significance of the difference in mean value between the placebo and the $\mathrm{Ob}-\mathrm{X}$ treated group was submitted to Student's t-test. ANCOVA analysis was also conducted. If the $\mathrm{p}$ value was smaller than 0.05 , the value was regarded as statistically significant. Correlations between initial values and changes in total abdominal, visceral, and subcutaneous fat areas were assessed using Pearson's correlation coefficient.

\section{Results}

3.1. Baseline Status and Compliance. As shown in Figure 1, of the total 80 subjects randomized, 58 completed the study. Of the 40 subjects in the placebo group, 25 completed the study. In the Ob-X treated group, 33 out of the 40 subjects completed the study. The noncompleters are represented by 8 subjects in the placebo group and 2 subjects in the $\mathrm{Ob}-\mathrm{X}$ treated group, who discontinued the study for personal reasons; 7 subjects in the placebo group and 5 subjects in $\mathrm{Ob}-\mathrm{X}$ treated group discontinued the study through loss to follow-up.

Of the 58 subjects who completed the study, 5 had compliance lower than $70 \%$ as described in the protocol. Therefore, 53 subjects completed the study according to the study protocol, and the results of these 53 subjects were analyzed, except for the safety analysis.

There were no significant differences between the characteristics of the groups at baseline, as shown in Table 1.

\subsection{Effect of $\mathrm{Ob}-\mathrm{X}$ on Abdominal Fat: Primary Outcome} Measure. To determine whether $\mathrm{Ob}-\mathrm{X}$ reduces fast-growing abdominal fat, visceral fat, and subcutaneous fat were assessed by computed tomography at baseline and at week 12 .

When we analyzed the change in abdominal fat by Ob-X at week 12 compared to the placebo group, the $\mathrm{Ob}-\mathrm{X}$ group reduced subcutaneous fat $\left(-8.33 \pm 51.63 \mathrm{~cm}^{2}\right.$ versus $1.56 \pm$ $39.88 \mathrm{~cm}^{2}$, respectively), visceral fat $\left(-30.23 \pm 27.28 \mathrm{~cm}^{2}\right.$ versus $-15.22 \pm 24.61 \mathrm{~cm}^{2}$ respectively), total abdominal fat $(-38.56$ $\pm 64.24 \mathrm{~cm}^{2}$ versus $-13.67 \pm 51.13 \mathrm{~cm}^{2}$ respectively), and visceral/subcutaneous fat ratio $(-0.14 \pm 0.17$ versus $-0.09 \pm$ 
TABLE 1: Characteristics of the subjects at baseline.

\begin{tabular}{cccc}
\hline & & $\begin{array}{c}\text { Placebo group } \\
(\mathbf{n}=\mathbf{2 3})\end{array}$ & $\begin{array}{c}\text { Ob-X group } \\
(\mathbf{n}=\mathbf{3 0})\end{array}$ \\
\hline Sex, $\mathrm{n}(\%)$ & Male (\%) & $2(8.7 \%)$ & $6(20 \%)$ \\
$24(80 \%)$ & $32.30 \pm 7.11$ \\
\hline Age $(\mathrm{y})$ & Female (\%) & $33.61 \pm 9.47$ & $162.70 \pm 7.74$ \\
\hline Height $(\mathrm{cm})$ & $159.90 \pm 5.62$ & $72.65 \pm 8.22$ \\
\hline Weight $(\mathrm{kg})$ & $69.99 \pm 6.27$ & $27.78 \pm 2.98$ \\
\hline BMI $\left(\mathrm{kg} / \mathrm{m}^{2}\right)$ & $27.33 \pm 1.27$ & $90.53 \pm 3.95$ \\
\hline Waist circumference $(\mathrm{cm})$ & $91.04 \pm 3.72$ & $102.14 \pm 4.29$ \\
\hline Hip circumference $(\mathrm{cm})$ & $101.58 \pm 3.85$ & $0.887 \pm 0.038$ \\
\hline Waist to hip ratio & $0.897 \pm 0.033$ & $119.53 \pm 11.31$ \\
\hline Systolic BP $(\mathrm{mmHg})$ & $115.65 \pm 10.37$ & $75.77 \pm 8.69$ \\
\hline Diastolic BP $(\mathrm{mmHg})$ & $74.70 \pm 10.61$ & $68.10 \pm 10.99$ \\
\hline Pulse (beats/min) & $66.52 \pm 10.92$ & \\
\hline
\end{tabular}

Values represent the mean $\pm \mathrm{SD}$.

TABLE 2: Changes in abdominal fat analyzed by computed tomography.

\begin{tabular}{lcccc}
\hline & Group & W0 & W12 & W12-W0 \\
\hline \multirow{2}{*}{ Subcutaneous fat $\left(\mathrm{cm}^{2}\right)$} & Placebo & $243.15 \pm 53.36$ & $244.71 \pm 55.18$ & $1.56 \pm 39.88$ \\
& Ob-X & $238.72 \pm 61.15$ & $230.38 \pm 57.67$ & $-8.33 \pm 51.63$ \\
\hline \multirow{2}{*}{ Visceral fat $\left(\mathrm{cm}^{2}\right)$} & Placebo & $141.68 \pm 47.60$ & $126.46 \pm 47.58$ & $-15.22 \pm 24.61$ \\
& Ob-X & $147.50 \pm 38.90$ & $117.27 \pm 26.42$ & $-30.23 \pm 27.28^{*}$ \\
\hline \multirow{2}{*}{ Total abdominal fat $\left(\mathrm{cm}^{2}\right)$} & Placebo & $384.83 \pm 55.79$ & $371.16 \pm 70.18$ & $-13.67 \pm 51.13$ \\
& Ob-X & $386.21 \pm 70.94$ & $347.65 \pm 63.67$ & $-38.56 \pm 64.24$ \\
\hline \multirow{2}{*}{ Visc.fat / Subc. fat ratio } & Placebo & $0.64 \pm 0.36$ & $0.55 \pm 0.30$ & $-0.09 \pm 0.15$ \\
& Ob-X & $0.68 \pm 0.27$ & $0.54 \pm 0.18$ & $-0.14 \pm 0.17$ \\
\hline
\end{tabular}

Values represent the mean $\pm \mathrm{SD}{ }^{*} \mathrm{p}<0.05$ compared with placebo.

0.15) as shown in Table 2 and Figure 2. However, there was statistical significance only in the reduction of visceral fat. The $\mathrm{Ob}-\mathrm{X}$ group showed a noticeable reduction in visceral fat of $20.5 \%$ after the 12 -week treatment as compared to baseline. The change in visceral fat in the Ob-X group was statistically significant as compared to the placebo group $(\mathrm{p}=0.0495)$ and 1.9 times higher than in the placebo group $(10.7 \%)$ as shown in Figure 3. The reduction of visceral fat by Ob-X was not the result of the decrease in calorie intake by appetite suppression, since there were no significant differences in calorie intake and energy consumption between the placebo group and the $\mathrm{Ob}-\mathrm{X}$ group at baseline and at week 12, as analyzed by nutrition analysis (data not shown).

This result indicates that the angiogenesis inhibitor, Ob$\mathrm{X}$, specifically reduces visceral fat, as angiogenesis occurs actively in fast-growing visceral fat.

3.3. The Correlation between Initial Values and Change of the Abdominal Fat Area. We examined the correlation between the initial visceral fat area and the change in visceral fat area induced by $\mathrm{Ob}-\mathrm{X}$ treatment. As shown in Figure 4, the change in visceral fat area induced by $\mathrm{Ob}-\mathrm{X}$ showed a significantly negative correlation with the initial visceral fat area $(\mathrm{r}=-0.75, \mathrm{p}=0.0000005)$. In contrast, no correlation was found between the initial visceral fat area and the placeboinduced change $(r=-0.28, p=0.16)$. A significantly negative correlation was also found between the initial subcutaneous fat area and the change in subcutaneous fat area induced by $\mathrm{Ob}-\mathrm{X}(\mathrm{r}=-0.47, \mathrm{p}=0.0050)$, but not in the placebo group $(\mathrm{r}$ $=-0.29, p=0.14)$. In addition, the change in total abdominal fat area induced by $\mathrm{Ob}-\mathrm{X}$ was also negatively correlated with the initial total abdominal fat area $(r=-0.56, p=0.0012)$, but not in the placebo group $(\mathrm{r}=-0.14, \mathrm{p}=0.52)$.

3.4. Effect of $\mathrm{Ob}$-X on Body Weight and Composition. Looking at the analysis data for other secondary outcome measurements, i.e., body weight, BMI, body fat composition, body fat mass, waist circumference, and WHR, there were no statistically significant differences on these variables between the placebo group and the Ob-X-treated group (Table 3). However, there was a trend towards the reduction in waist circumference and WHR in the Ob-X group. The waist circumference decreased by $4.24 \pm 4.29 \mathrm{~cm}$ in the $\mathrm{Ob}-\mathrm{X}$ treated group compared with a $3.97 \pm 5.17 \mathrm{~cm}$ decrease in the placebo group after 12 weeks of treatment. The change in waist-to-hip ratio was $-0.02 \pm 0.04$ in the $\mathrm{Ob}$ $\mathrm{X}$ treated group compared with $-0.01 \pm 0.04$ in the placebo group. 


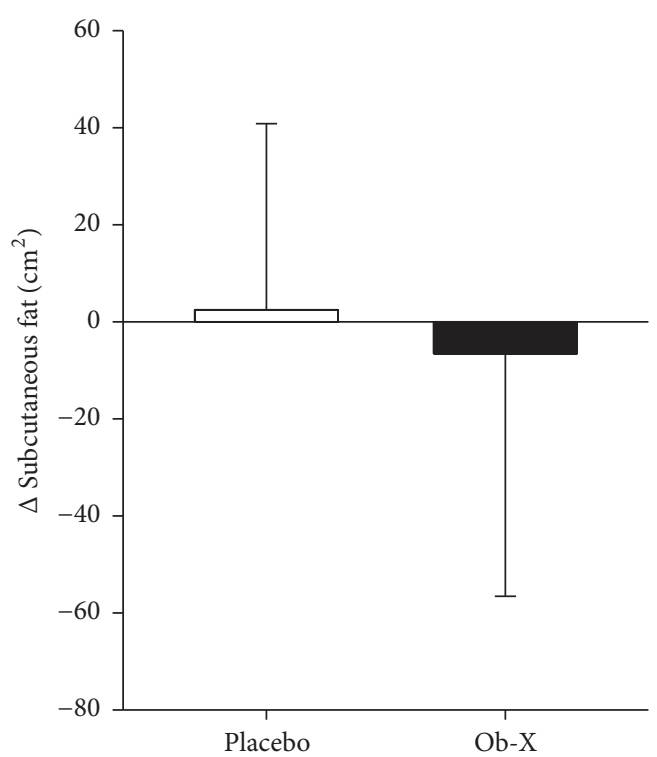

(a)

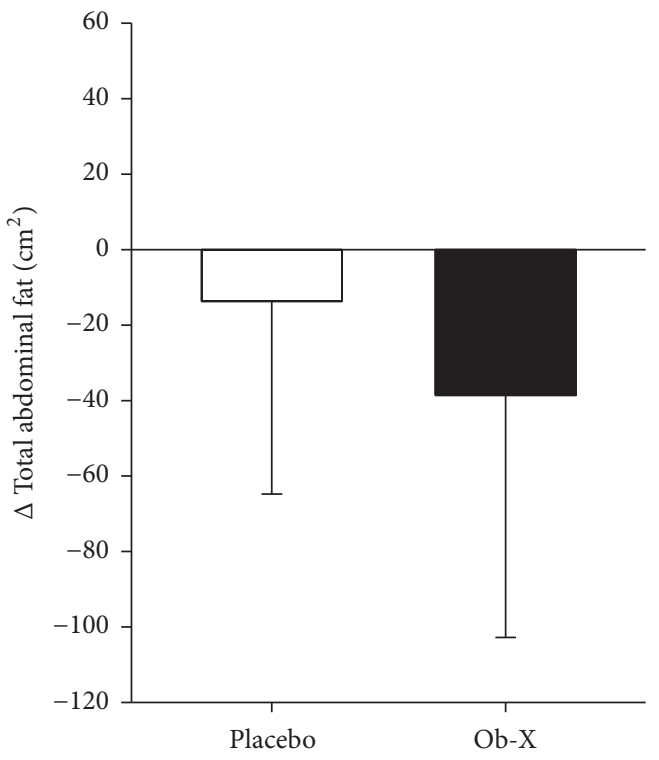

(c)

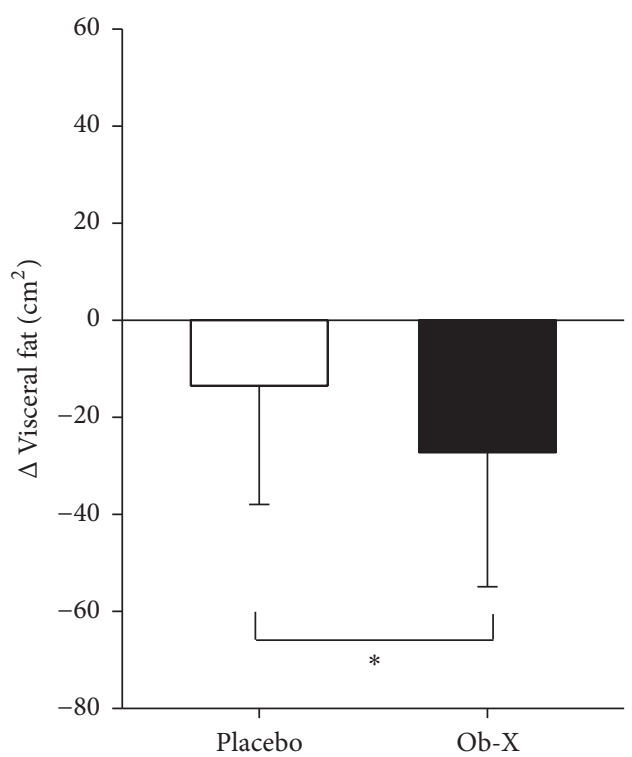

(b)

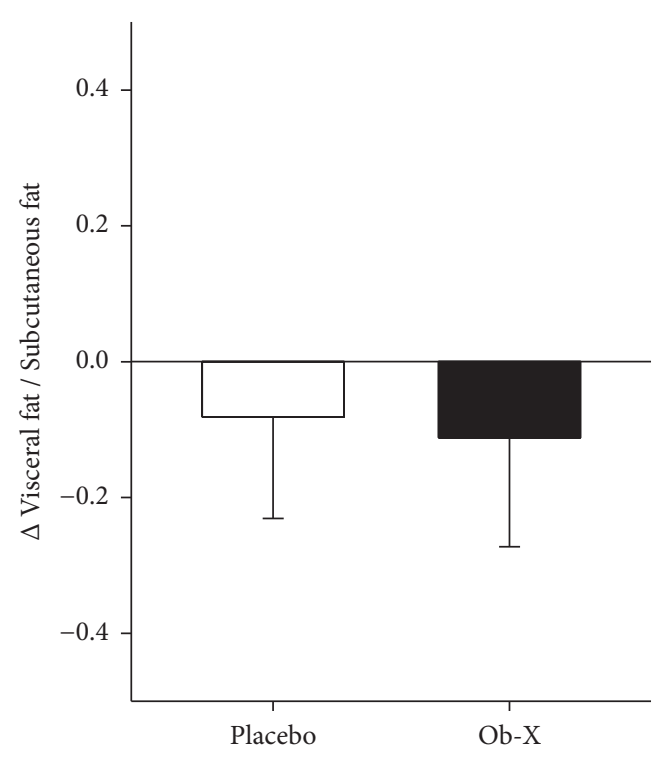

(d)

Figure 2: Changes in abdominal fat at week 12 of treatment with Ob-X. (a) Changes in subcutaneous fat, (b) visceral fat, (c) total abdominal fat, and (d) visceral fat/subcutaneous fat ratio $\left({ }^{*} \mathrm{p}<0.05\right.$ compared with placebo).

3.5. Serum Lipids and Others. In the serum analysis, there were no statistically significant changes between the placebo group and the $\mathrm{Ob}-\mathrm{X}$-treated group at baseline and at week 12, in terms of total cholesterol, LDL-cholesterol, HDLcholesterol, triglyceride, glucose, and CRP, which were all in the normal ranges in both groups (data not shown).

3.6. Safety Analysis. Adverse events were observed during the study period in the $\mathrm{Ob}-\mathrm{X}$ group and placebo group, as shown in Table 4. All these events were transient, and there was no observed aggravation due to the continuous intake of Ob-X capsules and the placebo capsules in each group. There was no difference between the groups in the incidence of selfreported adverse events.
The safety analysis for clinical laboratory test items (WBC, RBC, hematocrit, hemoglobin, platelet, creatinine, insulin, BUN, uric acid, $\mathrm{Ca}, \mathrm{P}, \mathrm{Na}, \mathrm{K}, \mathrm{Cl}, \mathrm{AST}$, ALT, albumin, protein, and ALP) and vital signs was conducted for 58 subjects (placebo: 25, Ob-X: 33), who were randomized and completed this study. There were no problematic abnormalities or findings. The mean values for all the clinical laboratory test items and vital signs from baseline to week 12 were in the normal range, and the changes were similar between the groups (data not shown). There was no statistical difference between the placebo and $\mathrm{Ob}-\mathrm{X}$ groups, from baseline to week 12. Based on these results, the safety of $\mathrm{Ob}-\mathrm{X}$ is similar to placebo, and it is considered that Ob-X has a good safety profile. 


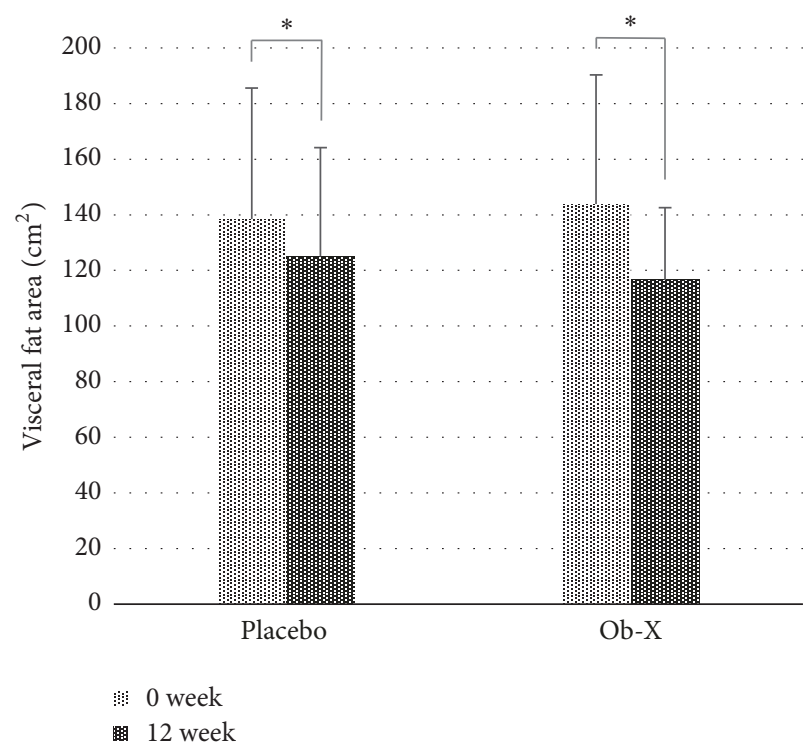

(a)

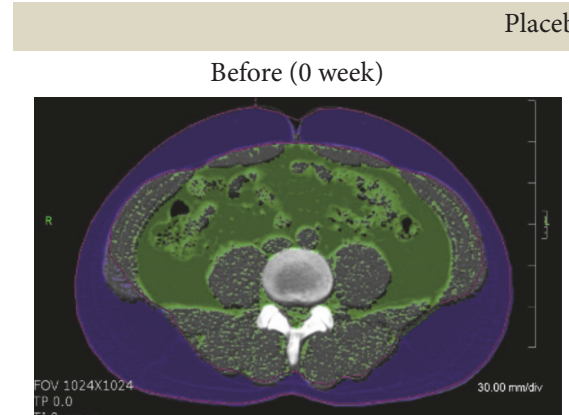

BMI: $27.33 \pm 1.27$

AVF: $141.68 \pm 47.60$

ASF: $243.15 \pm 53.36$

TAF: $384.83 \pm 55.79$

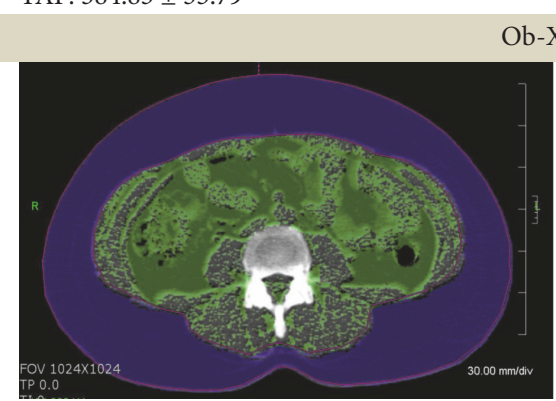

BMI: $27.78 \pm 2.98$

AVF: $147.50 \pm 38.90$

ASF: $238.72 \pm 61.15$

TAF: $386.21 \pm 70.94$

lacebo group

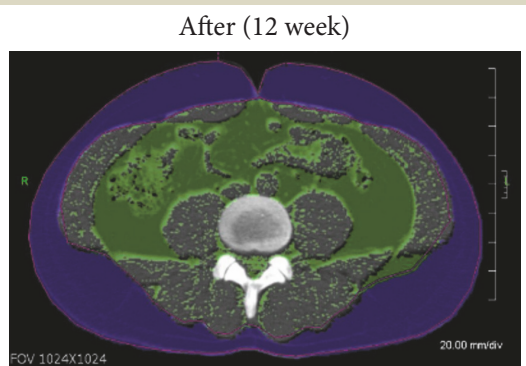

BMI: $26.08 \pm 1.31$

AVF: $126.46 \pm 47.58$

ASF: $244.71 \pm 55.18$

TAF: $371.16 \pm 70.18$

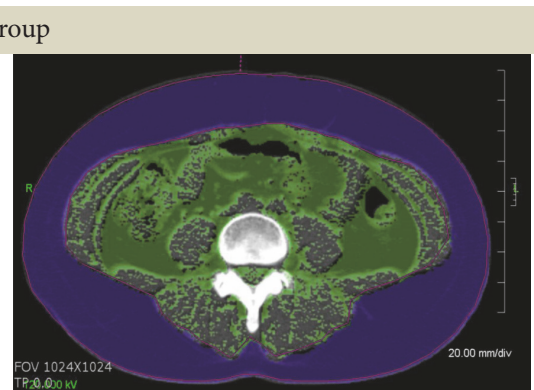

BMI: $26.43 \pm 1.82$

AVF: $117.27 \pm 26.42$

ASF: $230.38 \pm 57.67$

TAF: $347.65 \pm 63.67$

(b)

FiguRE 3: Reduction in visceral fat after 12-week treatment of Ob-X. (a) Visceral fat area was analyzed by computed tomography $\left({ }^{*} \mathrm{p}<\right.$ 0.05 compared with placebo). (b) Representative CT-scan data at 0 and 12 weeks in a subject from Ob-X or placebo group. Differences in abdominal visceral fat (AVF), abdominal subcutaneous fat (ASF), and total abdominal fat (ATF) areas at 0 and 12 weeks were measured. Computed tomography scanning for measuring fat area was performed with subject in the supine position, at the lumbar vertebra 4 level. Visceral fat area of the patient before and after Ob-X treatment was represented by the green color. Values represent the mean \pm SD. 


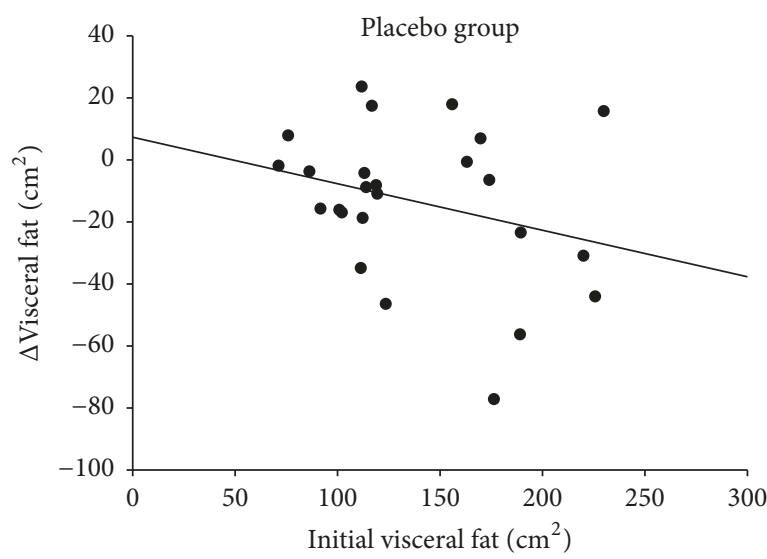

(a)

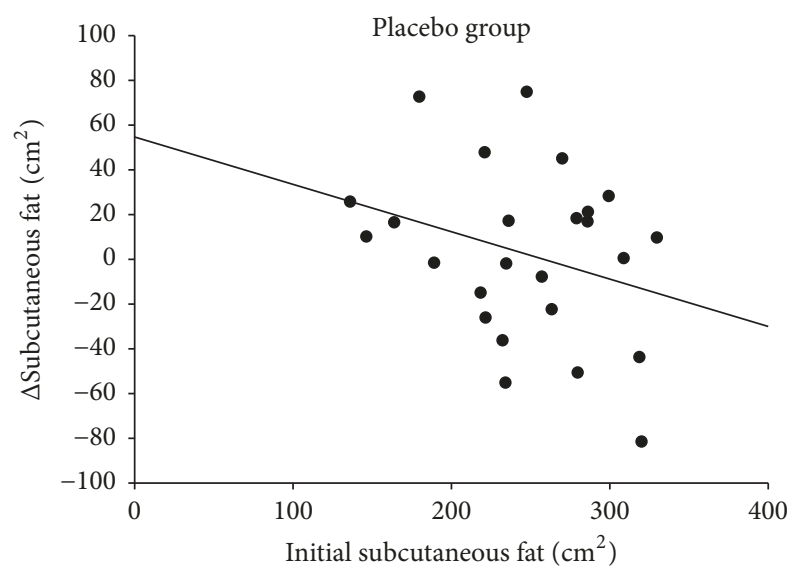

(c)

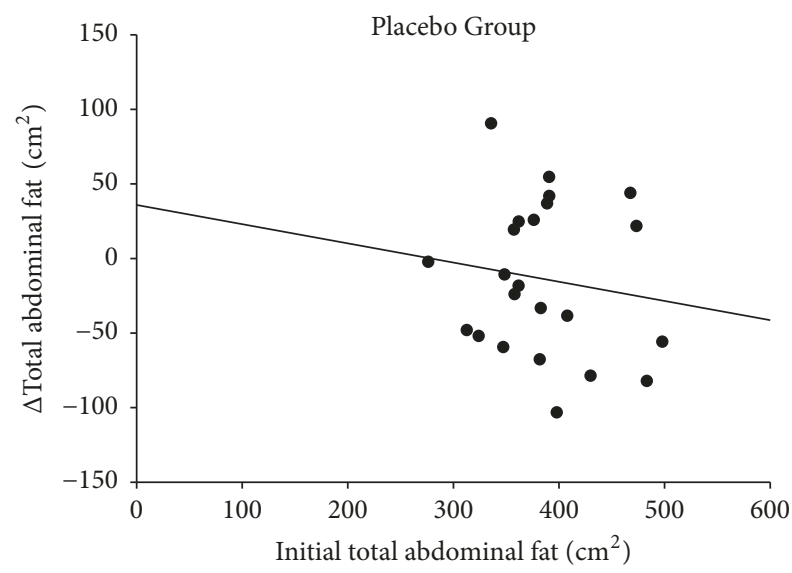

(e)

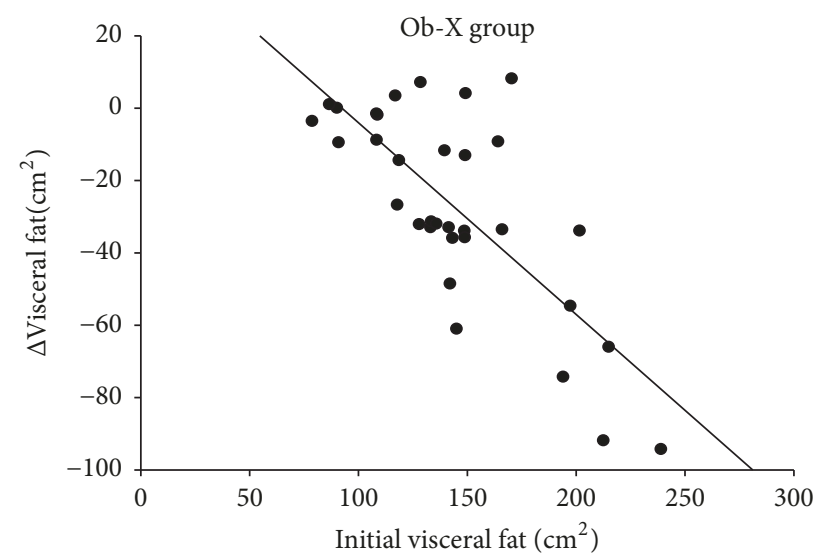

(b)

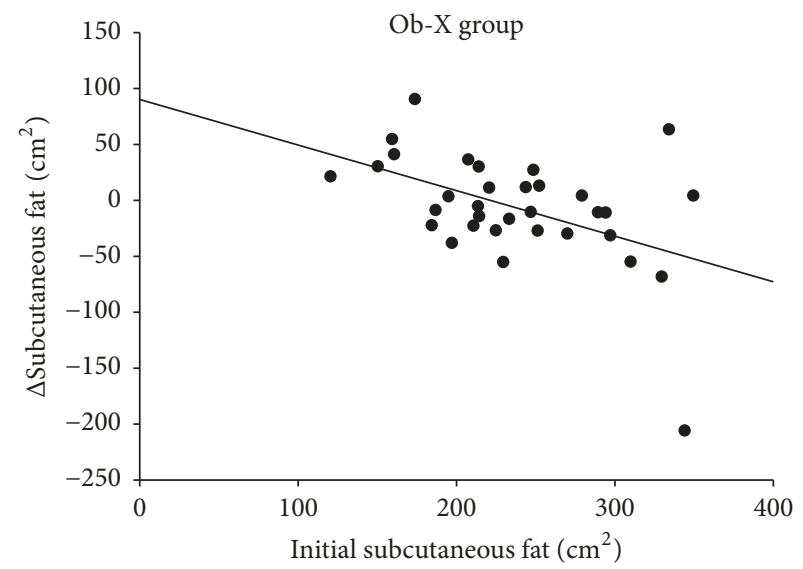

(d)

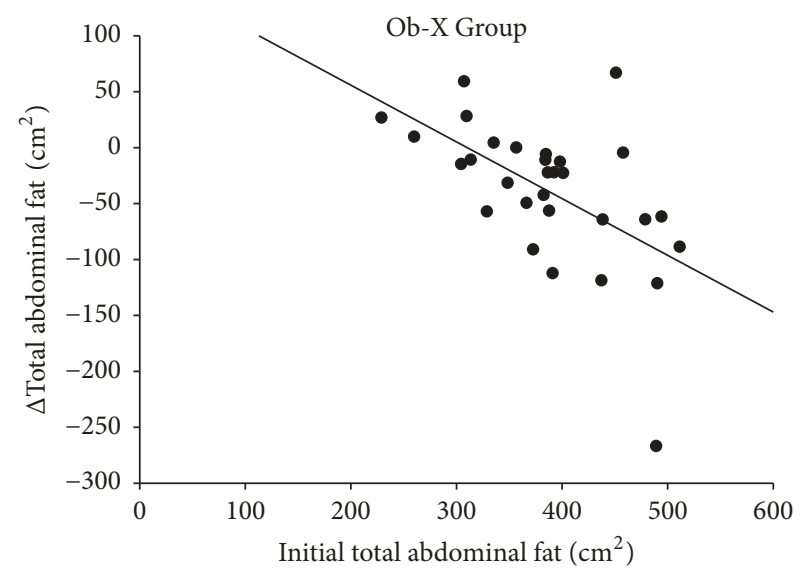

(f)

FIGURE 4: The fat reducing effect of placebo and $\mathrm{Ob}-\mathrm{X}$ treatment in relation to the initial abdominal fat area. Correlation between the induced change in visceral fat and initial visceral fat before intervention of placebo (a) or Ob-X (b). Correlation between the induced change in subcutaneous fat and initial subcutaneous fat before intervention of placebo (c) or Ob-X (c). Correlation between the induced change in total abdominal fat and initial total abdominal fat before intervention of placebo (e) or Ob-X (f).

\section{Discussion}

Angiogenesis has been shown to play a crucial role in the modulation of adipogenesis and obesity [14, 27]. Modulators of angiogenesis affect the expansion and metabolism of fat mass by regulating the growth and remodeling of the adipose tissue vasculature [15]. Therefore, pharmacological control of adipose tissue neovascularization by angiogenesis inhibitors might offer a novel therapeutic option for the treatment of obesity and related metabolic disorders [15].

The present study demonstrated, for the first time, that the angiogenesis inhibitor $\mathrm{Ob}-\mathrm{X}$ can reduce abdominal fat, especially visceral fat, in humans. $\mathrm{Ob}-\mathrm{X}$, which is composed 
TABLE 3: Changes from week 0 to week 12 between placebo and Ob-X treated group.

\begin{tabular}{lcccc}
\hline & Group & W0 & W12 & W12-W0 \\
\hline Body weight & Placebo & $69.99 \pm 6.27$ & $66.83 \pm 6.61$ & $-3.17 \pm 2.49$ \\
$(\mathrm{~kg})$ & Ob-X & $72.65 \pm 8.22$ & $70.07 \pm 7.75$ & $-2.58 \pm 2.97$ \\
\hline BMI $\left(\mathrm{kg} / \mathrm{m}^{2}\right)$ & Placebo & $27.33 \pm 1.27$ & $26.08 \pm 1.31$ & $-1.25 \pm 1.01$ \\
& Ob-X & $27.78 \pm 2.98$ & $26.43 \pm 1.82$ & $-1.34 \pm 2.35$ \\
\hline Body fat $(\%)$ & Placebo & $39.01 \pm 4.19$ & $36.93 \pm 1.15$ & $-2.08 \pm 2.24$ \\
$($ BIA) & Ob-X & $37.24 \pm 5.68$ & $35.44 \pm 6.10$ & $-1.80 \pm 2.90$ \\
\hline Body fat mass & Placebo & $27.30 \pm 3.88$ & $24.68 \pm 3.75$ & $-2.63 \pm 2.39$ \\
$(\mathrm{~kg})($ BIA) & Ob-X & $26.91 \pm 4.29$ & $24.65 \pm 4.24$ & $-2.26 \pm 2.94$ \\
\hline Waist circumference & Placebo & $91.04 \pm 3.72$ & $87.07 \pm 5.86$ & $-3.97 \pm 5.17$ \\
$(\mathrm{~cm})$ & Ob-X & $90.53 \pm 3.95$ & $86.29 \pm 5.84$ & $-4.24 \pm 4.29$ \\
\hline Hip circumference & Placebo & $101.58 \pm 3.85$ & $98.43 \pm 4.55$ & $-3.14 \pm 2.96$ \\
$(\mathrm{~cm})$ & Ob-X & $102.14 \pm 4.29$ & $99.56 \pm 4.05$ & $-2.58 \pm 3.13$ \\
\hline Waist / Hip & Placebo & $0.90 \pm 0.03$ & $0.88 \pm 0.05$ & $-0.01 \pm 0.04$ \\
ratio & Ob-X & $0.89 \pm 0.04$ & $0.87 \pm 0.05$ & $-0.02 \pm 0.04$ \\
\hline
\end{tabular}

Values represent the mean \pm SD. BMI, body mass index.

TABLE 4: Self-reported adverse events during 12 weeks of treatment.

\begin{tabular}{lcc}
\hline & Total number of cases & Adverse events (no. of case) \\
\hline Placebo & 15 & $\begin{array}{c}\text { Esophagitis(1), Headache(1), Edema(1), Nausea(1), Low back pain(1), } \\
\text { Enteritis(2), Menstrual irregularity(1), Cold/flu(7) }\end{array}$ \\
\hline Ob-X & 10 & $\begin{array}{c}\text { Heartburn(1), Constipation(1), Dry mouth(1), Cold/flu(3) } \\
\text { Stomachache(2), Menstrual irregularity(1), Meningitis(1), }\end{array}$ \\
\hline
\end{tabular}

of three herbal extracts, has synergistic effect on inhibition of angiogenesis when combined with three extracts comparing to a higher dose of a single extract [data not shown].

It is reported that vascular endothelial growth factor (VEGF) and its system account for most of the angiogenic activity in adipose tissue, making it an attractive target to reduce obesity [28-30]. Ob-X showed dose-dependent inhibition of VEGF-induced microvessel outgrowth from aortic tissue in the ex vivo rat aortic ring assay, indicating that $\mathrm{Ob}-\mathrm{X}$ can inhibit VEGF-induced angiogenesis [23]. Furthermore, in high fat diet-induced obese mice, Ob-X treatment reduced mRNA expression of VEGF in visceral and subcutaneous fat [23].

MMPs play major roles in the extracellular matrix remodeling events associated with angiogenesis [31, 32] and adipogenesis [33]. It was demonstrated that MMPs have novel function in adipogenesis, modulating adipocyte differentiation. Therefore, MMP inhibitors may block the adipocyte differentiation process [34-36]. In vitro and animal studies showed that $\mathrm{Ob}-\mathrm{X}$ can regulate the growth and development of adipose tissue by inhibiting MMP activities [23]. Thus, the mechanism of $\mathrm{Ob}-\mathrm{X}$ to reduce visceral fat in humans may be due to the inhibition of angiogenesis via the VEGF and MMP systems.

The $\mathrm{Ob}-\mathrm{X}$ reduced adipose tissue mass in nutritionally obese mice and the size of adipocytes in $\mathrm{Ob}-\mathrm{X}$ treated mice were markedly smaller than those in control mice. The size of visceral adipocytes was decreased by $63 \%$, while the size of subcutaneous adipocytes was decreased by $32 \%$ in $\mathrm{Ob}-\mathrm{X}$-treated mice relative to control mice. In addition, in
Ob-X-treated mice, the blood vessel density in visceral adipose tissue was lower than that of the controls, which shows that the decrease in visceral adipose tissue mass by $\mathrm{Ob}-$ $\mathrm{X}$ is the result of inhibition of angiogenesis [23].

Adipose tissue is one of the few adult tissues that can grow and regress throughout adulthood. This characteristic relies heavily on active angiogenesis, since the expansion of capillary beds is necessary for tissue growth. Accordingly, adipose tissue contains extensive capillary networks surrounding the adipocytes, which are probably induced by adipocytesecreted growth factors and hormones [37]. Adipose tissue has been shown to synthesize and release a huge number of signaling proteins, adipokines, which are involved in regulating many cellular processes, including inflammation and angiogenesis [37, 38]. Large-size adipocytes, mainly in visceral adipose tissue, are prone to rupture, evoking an inflammatory reaction [39]. In fact, we found that the size of visceral adipocytes is larger than that of subcutaneous adipocytes in high fat diet-induced obese mice [23], and angiogenesis occurs actively in visceral adipose tissue in which blood vessels are seen much more than in subcutaneous adipose tissue in animal experiments.

In a randomized placebo-controlled double-blind human study, Ob-X reduced total abdominal fat, subcutaneous fat, and visceral fat. However, a statistically significant reduction was shown only in visceral fat compared to placebo. The percentage of reduction in visceral fat by $\mathrm{Ob}-\mathrm{X}$ was $20.5 \%$ as compared to baseline (10.7\%), which was 1.9 times as much as placebo group. The selective effect of $\mathrm{Ob}-\mathrm{X}$ in reducing visceral fat may be attributed to the different properties of 
visceral fat and subcutaneous fat. Specifically, visceral fat is more sensitive to angiogenesis inhibitor, which is consistent with animal studies of Ob-X [23].

The effects of $\mathrm{Ob}-\mathrm{X}$ treatment in reducing visceral fat, subcutaneous fat, and total abdominal fat were negatively correlated with the initial areas of fat before intervention. The significantly negative correlation was the strongest in visceral fat. This implies that $\mathrm{Ob}-\mathrm{X}$ may have a strong effect in reducing visceral fat in individuals with high visceral fat.

Although $\mathrm{Ob}-\mathrm{X}$ reduced visceral fat in a statistically significant manner compared to the placebo group, we observed no effect on the other measurements related to visceral fat loss. The reduction in body fat mass and percentage body fat measured by BIA were not statistically significant compared to placebo. This may because the percentage of visceral fat in the total body fat is small, and $85 \%$ of the subjects were women, who have a larger proportion of fat in their body mass than men and are more likely to deposit fat subcutaneously [40]. In addition, when body composition was measured by BIA, which uses electric conductivity, we could not expect accuracy, given that factors that influence water content, such as water intake, perspiration, and urination and environment of measurement, are not considered.

No side effects were observed during the study period, and there were no statistically significant differences between the two groups. The adverse events reported in the Ob$\mathrm{X}$ group were common cold, heartburn, constipation, dry mouth, stomachache, menstrual irregularity, and meningitis, which were considered not to be related to Ob-X. The results for the safety analysis showed no significant differences between the placebo and $\mathrm{Ob}$-X-treated groups in the clinical laboratory blood test, biochemical test, blood pressure, and pulse. All the results were within normal ranges. The safety analysis suggested that $\mathrm{Ob}-\mathrm{X}$ is safe. Moreover, the good compliance and low dropout rates in the $\mathrm{Ob}-\mathrm{X}$ group indicate that $\mathrm{Ob}-\mathrm{X}$ can be administered for long-term use.

Many studies indicate that visceral adipose tissue, independent of obesity, is a major determinant of insulin resistance and contributes to variations in insulin sensitivity, even in healthy nonobese subjects [41]. Abdominal visceral fat is particularly harmful because it impairs insulin metabolism and promotes insulin resistance [42]. The mechanism by which visceral fat causes insulin resistance is known [43]. The expression of enzymes (e.g., lipoprotein lipase, hormone sensitive lipase, and peroxisome proliferator-activated receptor $\gamma$ ) related to lipid turnover in visceral fat increases with fat feeding in visceral fat relative to subcutaneous fat. This can enhance the flow of free fatty acids (FFA) through the portal vein to the liver, as well as to other tissues [43, 44]. FFA levels are frequently high in obese individuals, and experimental evidence suggests that high FFA and Low adiponectin plasma levels play a key role in the mechanism by which excess adiposity promotes insulin resistance $[45,46]$. Medina-Urrutia et al. also demonstrated the combined effect of high abdominal visceral fat and low adiponectin levels on the risk of insulin resistance [47].

Metabolic syndrome is a group of metabolic risk factors, including abdominal obesity, high blood pressure, high triglyceride levels, low levels of high density lipoprotein (HDL) cholesterol, and high levels of fasting plasma glucose [48]. Metabolic syndrome is associated with subsequent increases in the incidence of type 2 diabetes mellitus [49], cardiovascular disease morbidity [50], and even mortality [51]. It is becoming increasingly recognized that the most prevalent form of metabolic abnormalities linked to insulin resistance is found in patients with abdominal obesity, especially those with an excess of visceral adipose tissue [52]. The abdominal obesity is an essential criterion for diagnosis of metabolic syndrome defined by the International Diabetes Federation (IDF). Ethnic-specific waist circumference cut-off points have been incorporated in the definition. The cut-off value for waist circumference to define abdominal obesity in Koreans was $90 \mathrm{~cm}$ in men and $85 \mathrm{~cm}$ in women by the Korean Society of the Study of Obesity [53], which was the inclusion criteria in this study.

Hayashi et al. showed that visceral adiposity increases the odds of hypertension in Japanese Americans, independent of other adipose depots and fasting plasma insulin [54]. In addition, visceral and central abdominal fat showed a close association with type 2 diabetes in a case-control study involving 82 type 2 diabetic and 82 age- and sexmatched nondiabetic subjects [55]. It was also shown, in another human study, that visceral adiposity is a predictor of metabolic syndrome and cardiometabolic risk factor levels. Subjects whose maximum visceral adipose tissue area was higher in the abdomen had higher LDL-cholesterol concentrations, independent of age and adiposity [56]. Thus, visceral adipose tissue should be decreased to reduce the insulin resistance and the risk of metabolic syndrome. However, visceral fat is hard to lose by exercise only. It was reported that the high amount, vigorous intensity exercise equivalent to jogging 20 miles per week for about 8 months decreased the visceral fat by $6.9 \%$ [57]. In that regard, $20.5 \%$ decrease in visceral fat by $\mathrm{Ob}-\mathrm{X}$ was very efficient since it is an angiogenesis inhibitor reducing fast-growing visceral fat specifically. Although $\mathrm{Ob}-\mathrm{X}$ showed the decrease in blood vessels in visceral fat in animal study, further study will be necessary to analyze the angiogenic parameters in human blood.

\section{Conclusion}

The results of the present human study demonstrate that the angiogenesis inhibitor $\mathrm{Ob}-\mathrm{X}$ reduces visceral fat safely in humans. Therefore, it is expected that $\mathrm{Ob}-\mathrm{X}$ would reduce the risk of metabolic syndrome by reducing dangerous visceral fat.

\section{Conflicts of Interest}

The authors declare that they have no conflicts of interest.

\section{Acknowledgments}

This research was supported by the Small and Medium Business Administration (S1017496). 


\section{References}

[1] V. J. Carey, E. E. Walters, G. A. Colditz et al., "Body Fat Distribution and Risk of Non-Insulin-dependent Diabetes Mellitus in Women: The Nurses' Health Study," American Journal of Epidemiology, vol. 145, no. 7, pp. 614-619, 1997.

[2] J. M. Chan, E. B. Rimm, G. A. Colditz, M. J. Stampfer, and W. C. Willett, "Obesity, fat distribution, and weight gain as risk factors for clinical diabetes in men," Diabetes Care, vol. 17, no. 9, pp. 961969, 1994

[3] P. A. Cassano, M. R. Segal, P. S. Vokonas, and S. T. Weiss, "Body fat distribution, blood pressure, and hypertension. A prospective cohort study of men in the normative aging study," Annals of Epidemiology, vol. 1, no. 1, pp. 33-48, 1990.

[4] J. C. Seidell, M. Cigolini, J.-P. Deslypere, J. Charzewska, B.M. Ellsinger, and A. Cruz, "Body fat distribution in relation to serum lipids and blood pressure in 38-year-old European men: the European fat distribution study," Atherosclerosis, vol. 86, no. 2-3, pp. 251-260, 1991.

[5] A. H. Kissebah, S. Alfarsi, P. W. Adams, and V. Wynn, "Role of insulin resistance in adipose tissue and liver in the pathogenesis of endogenous hypertriglyceridaemia in man," Diabetologia, vol. 12, no. 6, pp. 563-571, 1976.

[6] K. M. Rexrode, V. J. Carey, C. H. Hennekens et al., "Abdominal adiposity and coronary heart disease in women," Journal of the American Medical Association, vol. 280, no. 21, pp. 1843-1848, 1998.

[7] M. Zamboni, F. Armellini, I. Sheiban et al., "Relation of body fat distribution in men and degree of coronary narrowings in coronary artery disease," American Journal of Cardiology, vol. 70, no. 13, pp. 1135-1138, 1992.

[8] P. Bjorntorp, "Abdominal obesity and the development of noninsulin-dependent diabetes mellitus," Diabetes/Metabolism Research and Reviews, vol. 4, no. 6, pp. 615-622, 1988.

[9] A. R. Folsom, S. A. Kaye, and T. A. Sellers, "Body fat distribution and 5-year risk of death in older women," The Journal of the American Medical Association, vol. 269, no. 4, pp. 483-487, 1993.

[10] A. R. Folsom, R. J. Prineas, S. A. Kaye, and R. G. Munger, "Incidence of hypertension and stroke in relation to body fat distribution and other risk factors in older women," Stroke, vol. 21, no. 5, pp. 701-706, 1990.

[11] M. A. Rupnick, D. Panigrahy, C.-Y. Zhang et al., "Adipose tissue mass can be regulated through the vasculature," Proceedings of the National Acadamy of Sciences of the United States of America, vol. 99, no. 16, pp. 10730-10735, 2002.

[12] L. Liu and M. Meydani, "Angiogenesis Inhibitors May Regulate Adiposity," Nutrition Reviews, vol. 61, no. 11, pp. 384-387, 2003.

[13] E. Bråkenhielm, R. Cao, B. Gao et al., "Angiogenesis inhibitor, TNP-470, prevents diet induced and genetic obesity in mice," Circulation Research, vol. 94, no. 12, pp. 1579-1588, 2004.

[14] Y. Cao, "Angiogenesis modulates adipogenesis and obesity," The Journal of Clinical Investigation, vol. 117, no. 9, pp. 2362-2368, 2007.

[15] Y. Cao, "Adipose tissue angiogenesis as a therapeutic target for obesity and metabolic diseases," Nature Reviews Drug Discovery, vol. 9, no. 2, pp. 107-115, 2010.

[16] J. S. Kim, B. Y. Park, E. K. Park et al., "Screening of antiangiogenic activity from plant extracts," Korean Journal of Pharmacognosy, vol. 37, pp. 253-257, 2006.

[17] M. Blumenthal, A. Goldberg, and J. Brinckmann, "Herbal Medicine-Expanded Commission E Mongraphs," MA: Integrative Medicine Communications, vol. 123, pp. 230-232, 2000.
[18] S. Akhondzadeh, M. Noroozian, M. Mohammadi, S. Ohadinia, A. H. Jamshidi, and M. Khani, "Melissa officinalis extract in the treatment of patients with mild to moderate Alzheimer's disease: a double blind, randomised, placebo controlled trial," Journal of Neurology, Neurosurgery \& Psychiatry, vol. 74, no. 7, pp. 863-866, 2003.

[19] M. Petersen and M. S. J. Simmonds, "Rosmarinic acid," Phytochemistry, vol. 62, no. 2, pp. 121-125, 2003.

[20] S.-S. Huang and R.-L. Zheng, "Rosmarinic acid inhibits angiogenesis and its mechanism of action in vitro," Cancer Letters, vol. 239, no. 2, pp. 271-280, 2006.

[21] N. Asano, H. Kizu, K. Oseki et al., "N-alkylated nitrogen-in-thering sugars: conformational basis of inhibition of glycosidases and HIV-1 replication," Journal of Medicinal Chemistry, vol. 38, no. 13, pp. 2349-2356, 1995.

[22] K. H. Han, Y. J. Jeon, Y. Athukorala et al., "A water extract of Artemisia capillaris prevents 2,2' -azobis(2-amidinopropane) dihydrochloride-induced liver damage in rats," Journal of Medicinal Food, vol. 9, no. 3, pp. 342-347, 2006.

[23] M.-Y. Kim, B. Y. Park, H. S. Lee et al., "The anti-angiogenic herbal composition $\mathrm{Ob}-\mathrm{X}$ inhibits adipose tissue growth in obese mice," International Journal of Obesity, vol. 34, no. 5, pp. $820-830,2010$.

[24] J. Lee, K. Chae, J. Ha et al., "Regulation of obesity and lipid disorders by herbal extracts from Morus alba, Melissa officinalis, and Artemisia capillaris in high-fat diet-induced obese mice," Journal of Ethnopharmacology, vol. 115, no. 2, pp. 263-270, 2008.

[25] M. Yoon and M.-Y. Kim, "The anti-angiogenic herbal composition Ob-X from Morus alba, Melissa officinalis, and Artemisia capillaris regulates obesity in genetically obese ob/ob mice," Pharmaceutical Biology, vol. 49, no. 6, pp. 614-619, 2011.

[26] Y. Hong, M.-Y. Kim, and M. Yoon, "The anti-angiogenic herbal extracts Ob-X from Morus alba, Melissa officinalis, and Artemisia capillaris suppresses adipogenesis in 3T3-L1 adipocytes," Pharmaceutical Biology, vol. 49, no. 8, pp. 775-783, 2011.

[27] H. R. Lijnen, "Angiogenesis and obesity," Cardiovascular Research, vol. 78, no. 2, pp. 286-293, 2008.

[28] D. Fukumura, A. Ushiyama, D. G. Duda et al., "Paracrine regulation of angiogenesis and adipocyte differentiation during in vivo adipogenesis." Circulation Research, vol. 93, no. 9, pp. e88-e97, 2003.

[29] G. J. Hausman and R. L. Richardson, "Adipose tissue angiogenesis," Journal of Animal Science, vol. 82, no. 3, pp. 925-934, 2004.

[30] G. Voros, E. Maquoi, D. Demeulemeester, N. Clerx, D. Collen, and H. R. Lijnen, "Modulation of angiogenesis during adipose tissue development in murine models of obesity," Endocrinology, vol. 146, no. 10, pp. 4545-4554, 2005.

[31] W. G. Stetler-Stevenson, "Matrix metalloproteinases in angiogenesis: a moving target for therapeutic intervention," The Journal of Clinical Investigation, vol. 103, no. 9, pp. 1237-1241, 1999.

[32] N. Hiraoka, E. Allen, I. J. Apel, M. R. Gyetko, and S. J. Weiss, "Matrix metalloproteinases regulate neovascularization by acting as pericellular fibrinolysins," Cell, vol. 95, no. 3, pp. 365-377, 1998.

[33] C. Pierleoni, F. Verdenelli, M. Castellucci, and S. Cinti, "Fibronectins and basal lamina molecules expression in human subcutaneous white adipose tissue," European Journal of Histochemistry, vol. 42, no. 3, pp. 183-188, 1998. 
[34] A. Bouloumié, C. Sengenès, G. Portolan, J. Galitzky, and M. Lafontan, "Adipocyte Produces Matrix Metalloproteinases 2 and 9 Involvement in Adipose Differentiation," Diabetes, vol. 50, no. 9, pp. 2080-2086, 2001.

[35] C. Chavey, B. Mari, M.-N. Monthouel et al., "Matrix metalloproteinases are differentially expressed in adipose tissue during obesity and modulate adipocyte differentiation," The Journal of Biological Chemistry, vol. 278, no. 14, pp. 11888-11896, 2003.

[36] E. Maquoi, C. Munaut, A. Colige, D. Collen, and H. Roger Lijnen, "Modulation of adipose tissue expression of murine matrix metalloproteinases and their tissue inhibitors with obesity," Diabetes, vol. 51, no. 4, pp. 1093-1101, 2002.

[37] S. Cinti, G. Mitchell, G. Barbatelli et al., "Adipocyte death defines macrophage localization and function in adipose tissue of obese mice and humans," Journal of Lipid Research, vol. 46, no. 11, pp. 2347-2355, 2005.

[38] I. F. Charo and R. M. Ransohoff, "The many roles of chemokines and chemokine receptors in inflammation," The New England Journal of Medicine, vol. 354, no. 6, pp. 610-621, 2006.

[39] R. Monteiro, P. M. S. T. De Castro, C. Calhau, and I. Azevedo, "Adipocyte size and liability to cell death," Obesity Surgery, vol. 16, no. 6, pp. 804-806, 2006.

[40] M. L. Power and J. Schulkin, "Sex differences in fat storage, fat metabolism, and the health risks from obesity: possible evolutionary origins," British Journal of Nutrition, vol. 99, no. 5, pp. 931-940, 2008.

[41] D. G. P. Carey, "Abdominal obesity," Current Opinion in Lipidology, vol. 9, no. 1, pp. 35-40, 1998.

[42] P. Björntorp, “"Portal” adipose tissue as a generator of risk factors for cardiovascular disease and diabetes," Arteriosclerosis, vol. 10, no. 4, pp. 493-496, 1990.

[43] M. Kabir, K. J. Catalano, S. Ananthnarayan et al., "Molecular evidence supporting the portal theory: A causative link between visceral adiposity and hepatic insulin resistance," American Journal of Physiology-Endocrinology and Metabolism, vol. 288, no. 2, pp. E454-E461, 2005.

[44] R. N. Bergman, S. P. Kim, K. J. Catalano et al., "Why visceral fat is bad: mechanisms of the metabolic syndrome," Obesity, vol. 14, supplement 1, pp. 16S-19S, 2006.

[45] A. M. F. Johnson and J. M. Olefsky, "The origins and drivers of insulin resistance," Cell, vol. 152, no. 4, pp. 673-684, 2013.

[46] C. Capurso and A. Capurso, "From excess adiposity to insulin resistance: the role of free fatty acids," Vascular Pharmacology, vol. 57, no. 2-4, pp. 91-97, 2012.

[47] A. Medina-Urrutia, C. Posadas-Romero, R. Posadas-Sánchez et al., "Role of adiponectin and free fatty acids on the association between abdominal visceral fat and insulin resistance," Cardiovascular Diabetology, vol. 14, pp. 20-27, 2015.

[48] Expert Panel on Detection, Evaluation, and Treatment of High Blood Cholesterol in Adults, "Executive Summary of The Third Report of The National Cholesterol Education Program(NCEP) Expert Panel on Detection, Evaluation, and Treatment of High Blood Cholesterol in Adults (Adult Treatment Panel III)", Journal of the American Medical Association, vol. 285, no. 19, pp. 2486-2497, 2001.

[49] D. E. Laaksonen, H.-M. Lakka, L. K. Niskanen, G. A. Kaplan, J. T. Salonen, and T. A. Lakka, "Metabolic syndrome and development of diabetes mellitus: application and validation of recently suggested definitions of the metabolic syndrome in a prospective cohort study," American Journal of Epidemiology, vol. 156, no. 11, pp. 1070-1077, 2002.
[50] A. Onat, K. Ceyhan, Ö. Başar, B. Erer, S. Toprak, and V. Sansoy, "Metabolic syndrome: major impact on coronary risk in a population with low cholesterol levels-a prospective and crosssectional evaluation," Atherosclerosis, vol. 165 , no. 2, pp. $285-$ 292, 2002.

[51] B. Isomaa, P. Almgren, T. Tuomi et al., "Cardiovascular morbidity and mortality associated with the metabolic syndrome," Diabetes Care, vol. 24, no. 4, pp. 683-689, 2001.

[52] J.-P. Després, I. Lemieux, and J. Bergeron, "Abdominal obesity and the metabolic syndrome: contribution to global cardiometabolic risk," Arteriosclerosis, Thrombosis, and Vascular Biology, vol. 28, no. 6, pp. 1039-1049, 2008.

[53] S. Y. Lee, H. S. Park, S. M. Kim et al., "Cut-off point of waist circumference for Defining Abdominal Obesity in the Korean Population," Korean Journal of Obesity, vol. 15, no. 1, pp. 1-9, 2006.

[54] T. Hayashi, E. J. Boyko, D. L. Leonetti et al., "Visceral adiposity and the prevalence of hypertension in Japanese Americans," Circulation, vol. 108, no. 14, pp. 1718-1723, 2003.

[55] M. Anjana, S. Sandeep, R. Deepa, K. S. Vimaleswaran, S. Farooq, and V. Mohan, "Visceral and central abdominal far and anthropometry in relation to diabetes in asian indians diabetes," Diabetes Care, vol. 27, no. 12, pp. 2948-2953, 2004.

[56] E. W. Demerath, D. Reed, N. Rogers et al., "Visceral adiposity and its anatomical distribution as predictors of the metabolic syndrome and cardiometabolic risk factor levels," American Journal of Clinical Nutrition, vol. 88, no. 5, pp. 1263-1271, 2008.

[57] C. A. Slentz, L. B. Aiken, J. A. Houmard et al., "Inactivity, exercise, and visceral fat. STRRIDE: A randomized, controlled study of exercise intensity and amount," Journal of Applied Physiology, vol. 99, no. 4, pp. 1613-1618, 2005. 


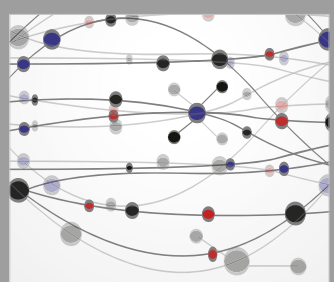

The Scientific World Journal
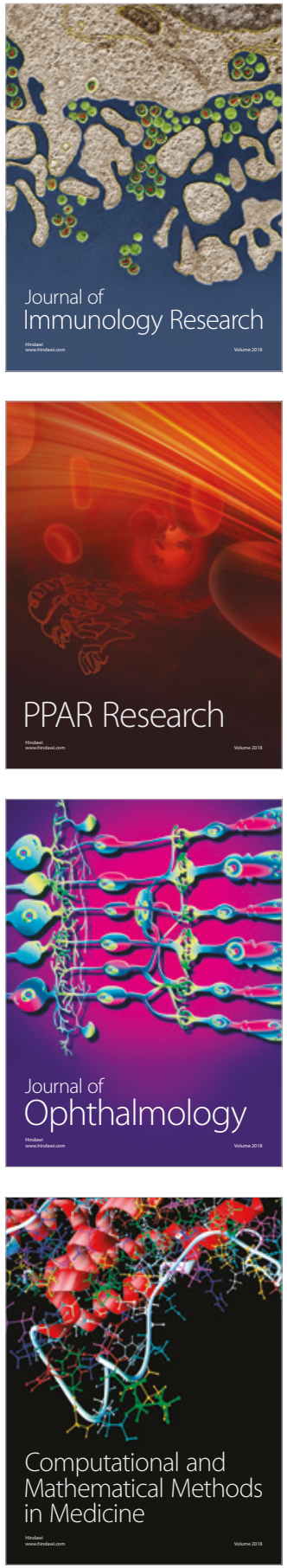

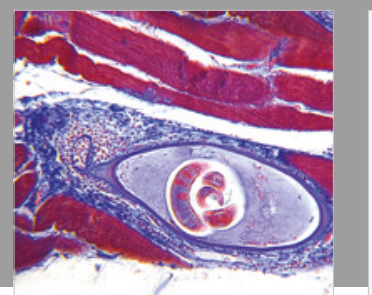

Gastroenterology Research and Practice

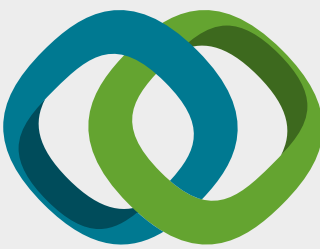

\section{Hindawi}

Submit your manuscripts at

www.hindawi.com
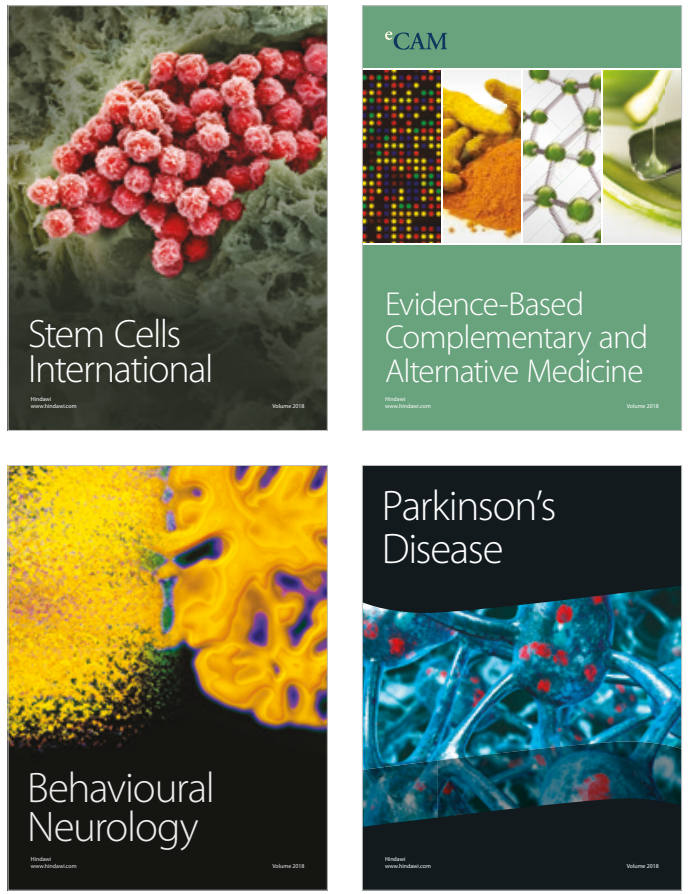

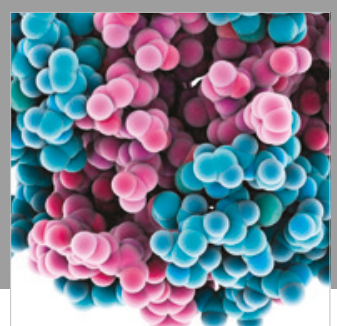

ournal of

Diabetes Research

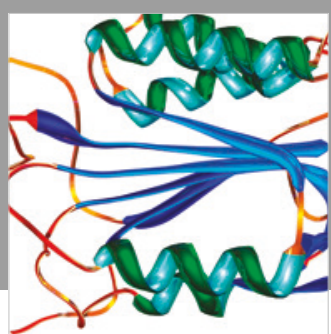

Disease Markers
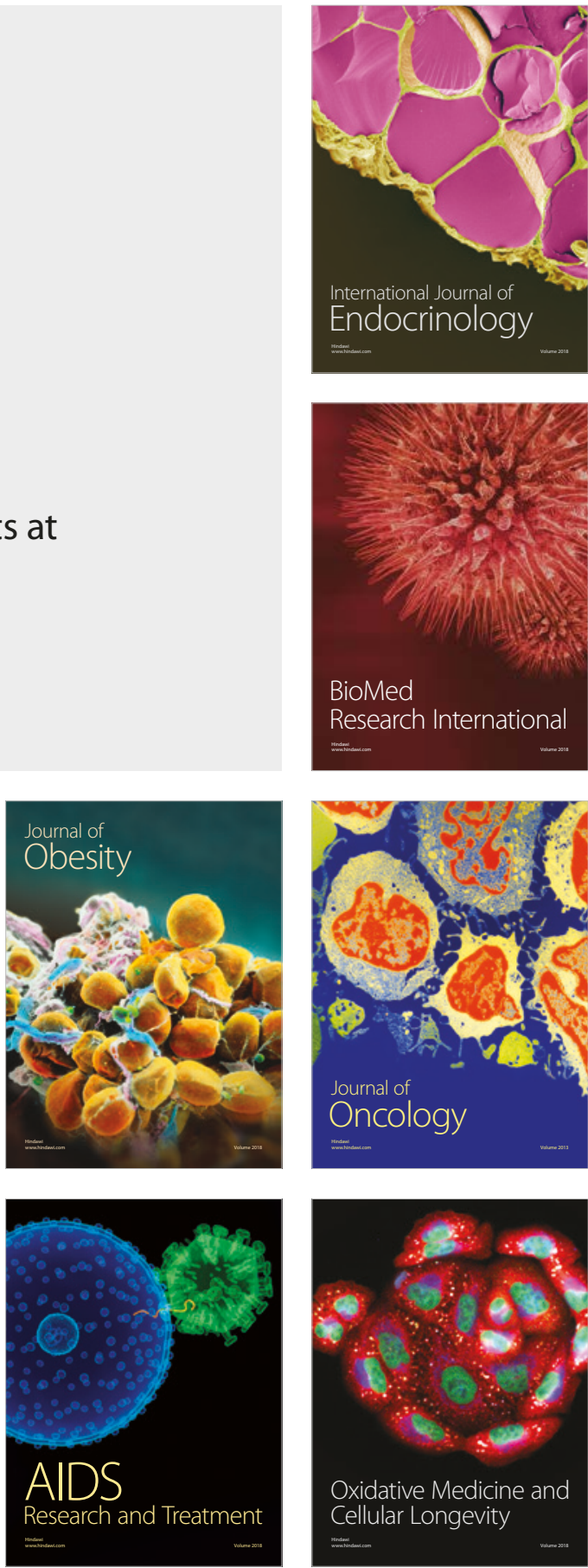